\title{
B. SCHWARTZ. LOS DIEZ MEJORES JUECES DE LA HISTORIA NORTEAMERICANA. CIVITAS. 1980. 109 PÁGINAS.
}

Este texto que constituye un volumen pequeño y que podría ser propio de un historiador nos muestra y demuestra la importancia de la judicatura y de los jueces en los Estados Unidos de Norteamérica. La idea no es nueva. Alexis de Tocqueville, gran observador francés de Estados Unidos de la primera mitad del siglo diez y nueve ya lo señalaba. Sin embargo, este texto nos señala el que los jueces en el país del norte pueden, sin lugar a dudas, convertirse en verdaderos organizadores del país.

El que sean organizadores de un país no sólo se presenta a través de la elaboración de sentencias que contengan una interpretación correcta de la ley sino que por lo que cada gran juez norteamericano pudo aportar en dicha sentencia (piénsese en "Marbury versus Madison" de Marshall) y de la capacidad, sea para interpretar el tiempo que les tocó vivir sea el que les tocaría vivir (el caso del juez Story) o la posibilidad de modificar la opinión de sus colegas a fin de adecuarlas a las nuevas concepciones acerca de justicia social (el juez Holmes).

En ningún caso son meros declarantes de la ley ya que ningún juez, en mi opinión, lo es. Ellos entregan aquellos elementos propios que los hacen ser ellos mismos y no otros y que les permiten decidir conforme a criterios estrictamente jurídicos, es cierto, pero utilizando en la medida de lo conveniente razonamientos que llevan a la altura de los tiempos al cuerpo al que pertenecen.

Lo anterior no deja de extrañar. Algunos de ellos, así lo señala el autor, no tienen un gran conocimiento o profundización en el Derecho y son más conocidos por su capacidad de determinar los problemas jurídicos (el caso de Marshall). ¿Es producto de la educación universitaria?. Indudablemente que no. Ello, en el caso de muchos de estos jueces, es producto del criterio jurídico y de entender el tema de su tiempo, su circunstancia. El gran juez Marshall, por ejemplo, no tuvo más de algunos años de estudios regulares. Por cierto, no como abogado o juez. Sin embargo, entendió aquello que estaba en el ambiente, utilizó su conocimiento jurídico limitado y generó ideas de profundidad y altura.

En este libro se analizan a los jueces Marshall, Story, Cardozo, Holmes, Warren, Kent, Shaw, Blck, Vanderbilt, Traynor.

Estudiando sólo aquellos aspectos que pueden ser de mayor importancia se observa la aplicación de conceptos relativos a la responsabilidad, en especial, extracontractual. Sin duda no deja de llamar la atención, el giro de una jurisprudencia que de un concepto subjetivo de responsabilidad (no hay responsabilidad sin culpa) pasa a un concepto objetivo de la misma. Ello dado que al inicio del industrialismo era necesaria una fórmula que solucionara el problema que tendría una industria naciente al pagar la indemnización correspondiente. En este caso la responsabilidad la asume la sociedad. Sin embargo, luego del desarrollo industrial en Estados Unidos tuvo que asumir la responsabilidad el que genera el problema y no la sociedad toda.

Así, en definitiva, se observa en múltiples ámbitos de lo jurídico la incidencia de la Corte Suprema Norteamericana y su búsqueda en la adecuación del Derecho a las 
circunstancias que se viven (sin ser oportunistas, obviamente) e incluso, el imprimir rumbo a Estados Unidos en una u otra dirección a través de sus decisiones. 